\title{
Polyphenols from marine brown algae target radiotherapy-coordinated EMT and stemness- maintenance in residual pancreatic cancer
}

Sheeja Aravindan ${ }^{1,2}$, Satish Kumar Ramraj ${ }^{3}$, Somasundaram T. Somasundaram', Terence S. Herman ${ }^{3}$ and Natarajan Aravindan ${ }^{3^{*}}$

\begin{abstract}
Introduction: Therapy-associated onset of stemness-maintenance in surviving tumor-cells dictates tumor relapse/ recurrence. Recently, we recognized the anti-pancreatic cancer (PC) potential of seaweed polyphenol manifolds and narrowed down three superior drug-deliverables that could serve as adjuvants and benefit PC cure. Utilizing the PC- cancer stem cells (PC-CSCs) grown ex vivo and mouse model of residual-PC, we investigated the benefits of seaweed polyphenols in regulating stemness-maintenance.
\end{abstract}

Methods: $\mathrm{ALDH}^{+} \mathrm{CD} 44^{+} \mathrm{CD} 24^{+}$PC-CSCs from Panc-1, Panc-3.27, MiaPaCa-2, or BxPC-3 cells-derived xenografts grown ex vivo were either mock-irradiated, exposed to fractionated irradiation (FIR, 2Gy/D for 5 days), treated with polyphenols $(100 \mathrm{\mu g} / \mathrm{ml})$ of Hormophysa triquerta (HT-EA), Spatoglossum asperum (SA-EA) or Padina tetrastromatica (PT-EA) with/ without FIR were examined for cell viability, transcription of 93 stem-cell-related molecules (QPCR profiling). Polyphenol-dependent regulation of FIR-transactivated Oct4, Zic3, EIF4C, Nanog, and LIF (QPCR) and functional translation of Nanog, SOX2, and OCT3/4 (immunoblotting) were examined in Panc-1/Panc-3.27/MiaPaCa-2/BxPC3-xenografts derived PC-CSCs. Effect of seaweed-polyphenols in the regulation of EMT (N-Cadherin), pluripotency(SOX2, OCT3/4, Nanog) and stemness-maintenance (PI3KR1, LIF, CD44) in therapy (FIR, 2Gy/D for 5D/wk for 3-weeks) resistant residual tumors were examined by tissue microarray construction and automated immunohistochemistry.

Results: Ex vivo exposure of PC-CSCs to SA-EA, PT-EA and HT-EA exhibit dose-dependent inhibition of cell viability. FIR amplified the transcription of 69, 80, 74 and 77 stem-cell related genes in MiaPaCa-2-, Panc-1-, Panc3.27- and BXPC3-established xenograft-derived $\mathrm{ALDH}^{+} \mathrm{CD} 44^{+} \mathrm{CD} 24^{+} \mathrm{PC}-\mathrm{CSC}$. Treatment with SA-EA, PT-EA, or HT-EA completely suppressed FIR-activated stem-cell transcriptional machinery in $\mathrm{ALDH}^{+} \mathrm{CD} 44^{+} \mathrm{CD} 24^{+} \mathrm{PC}$-CSCs established from MiaPaCa-2, Panc-1, Panc-3.27 and BXPC3 xenografts. QPCR validated EIF4C, OCT3/4, Nanog, LIF, and ZIC3 transcriptional profile outcomes. Nanog, Sox2, and OCT3/4 immunoblotting affirmed the PC-CSC radiosensitizing benefit of seaweed polyphenols. Residual-PC tissues microarrayed and immunostained after in vivo treatments recognized complete regulation of FIR-induced SOX2, OCT3/4, Nanog, LIF, CD44, PIK3R1, N-Cadherin, and E-Cadherin with SA-EA, PT-EA, and HT-EA.

Conclusions: These data, for the first time, documented the EMT/stemness-maintenance in therapy-resistant PC-CSCS. Further, the data suggest that seaweed polyphenols may inhibit PC relapse/recurrence by targeting therapy-orchestrated stem-cell signaling in residual cells.

\footnotetext{
* Correspondence: naravind@ouhsc.edu

${ }^{3}$ Department of Radiation Oncology, University of Oklahoma Health Sciences

Center, 940 Stanton L. Young Boulevard, Oklahoma City, OK 73104, USA

Full list of author information is available at the end of the article
}

C Biomed Central
(C) 2015 Aravindan et al. Open Access This article is distributed under the terms of the Creative Commons Attribution 4.0 International License (http://creativecommons.org/licenses/by/4.0/), which permits unrestricted use, distribution, and reproduction in any medium, provided you give appropriate credit to the original author(s) and the source, provide a link to the Creative Commons license, and indicate if changes were made. The Creative Commons Public Domain Dedication waiver (http://creativecommons.org/publicdomain/zero/1.0/) applies to the data made available in this article, unless otherwise stated. 


\section{Introduction}

Clinical and laboratory evidence suggests that several common human cancers contain populations of rapidly proliferating clonogens that can have a substantial impact on local control following chemoradiotherapy or conventional radiotherapy [1]. Recurring tumors may arise from remnant cells of the original neoplasm that have escaped therapeutic intervention and later become visible at the original site [2,3]. For many cancers, it has been hypothesized that tumor cells responsible for failures in long-term remission exhibit stem cell properties [4-6]. It is now being appreciated that tumors contain a small number of tumor-forming and self-renewing cancer stem cells (CSCs) within a population of nontumor-forming cancer cells that contribute to pancreatic cancer (PC) progression and relapse [7]. The CSC hypothesis suggests that conventional chemoradiotherapy kills differentiated/differentiating cells that form the bulk of the tumor, but cannot generate new cells. Tumor relapse may occur because CSCs remain untouched by treatment, suggesting that the removal of CSCs is crucial for effective therapy. In addition, recent evidence points to the existence of programmed functional plasticity not only in CSCs, but also in nonstem cancer cell populations [8, 9]. Detailed pathological analysis of PC has confirmed genetically traceable unique subclone association with metastatic lesions $[10,11]$, and further suggests that multiple genetic subclones are constantly evolving, competing in parallel within the primary tumor, and might independently give rise to metastatic lesions. In addition, recent genetic profiles of CSCs [12] demonstrated genetically diverse tumor-initiating cells in genetically-driven tumors. As CSCs have been shown to be more resistant to chemoradiation than the rest of the tumor cell population [13-16], this selective pressure would automatically select the genetic clones that contain a higher proportion of CSCs, and thereby have greater potential for reconstituting tumor growth once the therapeutic regimen is finished. In this regard, delineating the contribution of reactivated (after first-line therapy) developmental signaling pathways to PC initiation and progression [17] would shed light on understanding the CSCs' role in $\mathrm{PC}$ progression and relapse.

Early forays into CSC-targeted therapies in combination with standard therapies $[18,19]$ have shown that some combinations have efficacy against PC-CSCs $[20,21]$, decreased tumorosphere-forming capacity, and in vivo tumorigenicity. These approaches reveal the possibility of developing CSC-targeted therapies that could potentially be used alongside chemotherapy and radiation to specifically eliminate CSC subpopulations and reduce tumor recurrence. Seaweeds rich in polyphenols [22] have been shown to exert anti-tumor [23] potential, particularly in inhibiting cell proliferation [24], tumor regression [25], and inhibition of metastasis [26]. A close association between polyphenols' anti-carcinogenic activity and antioxidant activity has been reported in mouse models of carcinoma [25, 27]. Recent investigations demonstrated the anti-proliferative, pro-apoptotic, DNA-damaging, antiangiogenic, growth-inhibiting, cell-cycle arrest, and antimetastatic functions of seaweed extracts in various tumor models [28-31]. We have recently demonstrated that polarity-based polyphenol fractions extracted from brown algae exerted potent anti-PC potentials in vitro, and further identified three high-polarity fractions that could be clinically translatable [32]. This study defined the therapy-associated stem cell-related molecular signature in residual $\mathrm{ALDH}^{+} \mathrm{CD} 44^{+} \mathrm{CD} 24^{+} \mathrm{PC}-\mathrm{CSC}$, and further identified the clinical benefits of these fractions in this setting.

\section{Methods and materials}

\section{Cell culture}

Genetically diverse human Panc-1, MiaPaCa-2, Panc3.27 , and BxPC-3 cells were cultured and maintained as described earlier [32, 33].

\section{Xenotransplantation mouse model}

All experiments conformed to American Physiological Society standards for Animal Care, were carried out in accordance with the guidelines laid down by the National Research Council, and were approved by the University of Oklahoma Health Sciences Center Institutional Animal Care and Use Committee. Seven-week-old male athymic $\mathrm{NCr}-n u / n u$ nude mice weighing 25-30 g were acclimatized for at least 3 days before the study. We administered $5 \times 10^{6}$ Panc-1, Panc-3.27, MiaPaCa-2, or BxPC-3 cells (with $30 \%$ Matrigel; Corning, Tewksbury, MA, USA) subcutaneously into their right flanks. Tumor growth was periodically monitored and was allowed to grow to a volume of at least $100 \mathrm{~mm}^{3}$.

\section{Isolation of PC-CSCs}

PC-CSCs from Panc-1, Panc-3.27, MiaPaCa-2, or BxPC-3 cell-derived xenografts were isolated by flow cytometry [34]. Briefly, dissociated cells were pelleted, resuspended in ALDEFLUOR buffer, and sorted by defining their phenotypes with parallel controls. We adopted the sequential exclusion $\rightarrow$ inclusion criteria to isolate human $\mathrm{ALDH}^{+}$ $\mathrm{CD} 44^{+} \mathrm{CD} 24^{+}$PC-CSCs from the xenograft. Cells were divided into seven groups: unstained, $\mathrm{CD} 24^{+} \mathrm{PE}, \mathrm{CD} 44^{+} \mathrm{APC}$, mouseCD31- biotin $^{+}$mouse lineage biotin $^{+}$mouse $\mathrm{H}_{2} \mathrm{Kd}^{-}$ biotin, ALDEFLUOR, ALDEFLUOR ${ }^{+} \mathrm{DEAB}^{+} \mathrm{IgG}_{2} \mathrm{bK}^{-} \mathrm{APC}^{+}$ IgG2ak ${ }^{-} \mathrm{PE}$, and $\mathrm{ALDEFLUOR}{ }^{+} \mathrm{CD} 44^{+} \mathrm{APC}^{+} \mathrm{CD} 24 \mathrm{PE}^{+}$mouseCD31 ${ }^{-}$biotin $^{+}$mouse-lineage ${ }^{-}$biotin $^{+}$mouse- $\mathrm{H}-2 \mathrm{Kd}^{-}$biotin. CSCs were screened based on $\mathrm{CD} 24^{+} \mathrm{CD} 44^{+} \mathrm{ALDH}^{+}$subtypes (Fig. 1a). $\mathrm{ALDH}^{+} \mathrm{CD} 44^{+} \mathrm{CD} 24^{+}$PC-CSCs characterized and isolated from the xenografts established using MiaPaCa-2, 

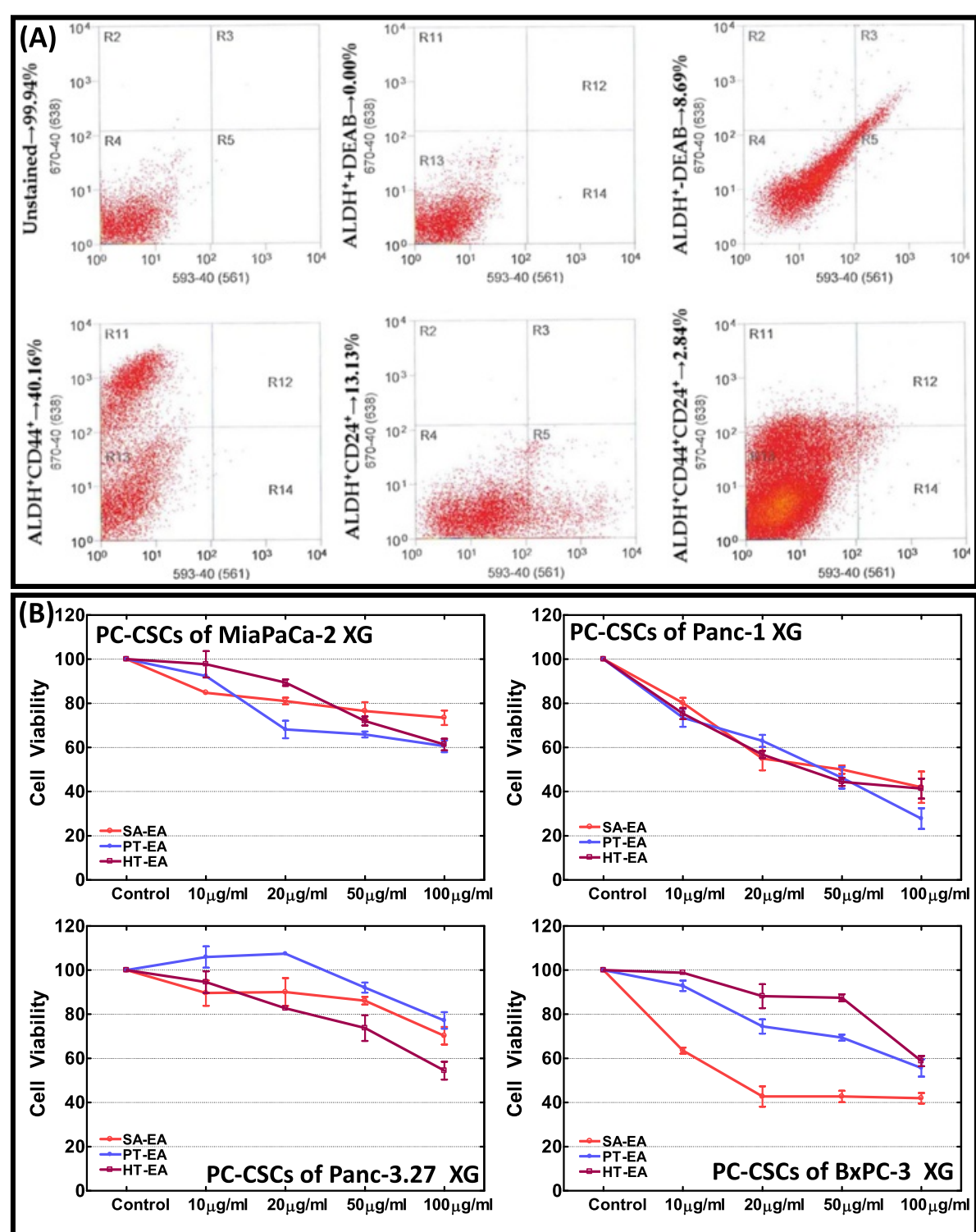

Fig. 1 a Flow cytometry plots showing populations from human $\mathrm{PC}$ xenografts. $\mathrm{Pl}^{+}$, mouse-CD31 ${ }^{+}$mouse-lineage ${ }^{+}$, or mouse- $\mathrm{H}-2 \mathrm{Kd}{ }^{+}$cells are excluded in order to isolate only viable nonmouse-derived cells. ALDH activity was measured using ALDEFLUOR reagent (Aldefluor Kit, Stem Cell Technologies, Vancouver, BC, Canada) in the presence/absence of N,N-diethylaminobenzaldehyde (DEAB) . The CD44 ${ }^{+} \mathrm{CD} 24^{+}$gate was created based on cells stained with ALDEFLUOR, and lgG2bk-APC (isotypic control) and lgG2ak-PE (isotypic control) antibodies. Percentage of ALDH ${ }^{+} \mathrm{CD} 44^{+} \mathrm{CD} 24^{+}$ cells is given in the text. $\mathbf{b}$ Line plots showing cell-viability dose-response curves of PC-CSCs exposed to seaweed polyphenols. PC-CSCs derived from xenografts established using MiaPACa-2, Panc-1, Panc-3.27, or BXPC-3 cells were exposed to increasing concentrations (10, 20, 50, or 100 $\mu$ g/ml) of SA-EA, PT-EA, or HT-EA and examined for alterations in cell viability using the automated countess trypan blue exclusion assay. Treatment with seaweed polyphenols exhibited dose-dependent inhibition of PC-CSC cell viability with maximum inhibition at $100 \mu \mathrm{gg} / \mathrm{ml}$. The dose-dependent decrease in cell viability by SA-EA, HT-EA, and PT-EA remained consistent in all four PC-CSC clones investigated. ALDH aldehyde dehydrogenase, CSC cancer stem cell, HT-EA ethyl acetate polyphenol fraction of Hormophysa triquerta, PC pancreatic cancer, PT-EA ethyl acetate polyphenol fraction of Padina tetrastromatica, SA-EA ethyl acetate polyphenol fraction of Spatoglossum asperum

Panc-1, Panc-3.27, and BXPC-3 were discretely collected and maintained ex vivo in stem cell medium (cell-line specific basal-medium without fetal bovine serum (FBS), complemented with $40 \mathrm{ng} / \mathrm{ml}$ epidermal growth factor (EGF), $10 \mathrm{ng} / \mathrm{ml}$ fibroblast growth factor (FGF), B27, N2 supplements). All sorted $\mathrm{ALDH}^{+} \mathrm{CD} 44^{+} \mathrm{CD} 24^{+}$PC-CSCs exhibited tumorosphere formation under serum-free controlled conditions ex vivo (Figure S1A in Additional file 1).

\section{In vitro and in vivo irradiation procedures}

$\mathrm{ALDH}^{+} \mathrm{CD} 44^{+} \mathrm{CD} 24^{+} \mathrm{PC}$-CSCs grown ex vivo were either mock irradiated or exposed to fractionated irradiation (FIR, 
2 Gy/D for 5 days) using a Gamma Cell 40 Exactor (Best Theratronics, Ottawa, ON, Canada) at a dose rate of $0.81 \mathrm{~Gy} / \mathrm{minute}$. In vivo PC xenografts were selectively exposed to FIR ( 2 Gy/day for 5 days per week for 3 weeks) to a total dose of $30 \mathrm{~Gy}$. A specially designed cerrobend shield was used to encase the bodies of the mice, exposing only the flank tumors, as described earlier [35-37]. Dosimetry was measured using both thermoluminescent and radiochromic film dosimetry [35]. Mock-irradiated animals were treated identically, except that they were not subjected to radiation.

\section{Polyphenol treatments}

Polarity-based extractions of seaweed polyphenols were performed as described earlier [32]. For this study, ethyl acetate fractions of Hormophysa triquerta (HT-EA), Spatoglossum asperum (SA-EA), and Padina tetrastromatica (PT-EA) were selectively examined. Seaweeds are collected as a part of the Department of Science and Technology, Government of India-sponsored DBT project and, since this collection does not involve any endangered or protected species, no specific permissions were required (Forest Department, Government of India exempt). In brief, freshly collected, oven-dried, and powdered algae (50 g) was subjected to sequential extraction in gradient (increasing) polarity solvents including hexane, dichloromethane, ethyl acetate, and methanol for $48 \mathrm{~h}$ each at room temperature. The slurry in each phase was filtered and the residue was subjected for extraction in the subsequent solvent. The dried filtrates were weighed and dissolved in dimethyl sulfoxide (DMSO) to a stock concentration of $100 \mathrm{mg} / \mathrm{ml}$. For cell treatment, stock solutions were diluted in plain cell culture medium to a "working" concentration of $10 \mathrm{mg} / \mathrm{ml}$. For all ex vivo investigations, $\mathrm{ALDH}^{+} \mathrm{CD} 44^{+} \mathrm{CD} 24^{+} \quad \mathrm{PC}-\mathrm{CSC}$ were treated with $100 \mu \mathrm{g} / \mathrm{ml}$ of each polyphenol fraction, while a corroborated $10 \mathrm{mg} / \mathrm{kg}$ concentration was used for in vivo studies. The final concentration of DMSO in the cell culture medium was $0.0001 \%$.

\section{Cell viability}

The trypan blue exclusion assay utilizing an automated countess was used to identify the efficacy of polyphenols in the regulation of $\mathrm{PC}-\mathrm{CSC}$ cell viability. $\mathrm{ALDH}^{+} \mathrm{CD} 44$ ${ }^{+} \mathrm{CD}_{24}{ }^{+}$PC-CSCs (derived from xenografts established using MiaPaCa-2, Panc-1, Panc-3.27, and BxPC-3 cells) grown ex vivo were treated with $10,20,50$, or $100 \mu \mathrm{g} / \mathrm{ml}$ SA-EA, PT-EA, or HT-EA, and were examined after $18 \mathrm{~h}$ for alterations in cell viability, as described earlier [33].

\section{Stem cell-related transcriptome profiling}

Total RNA extraction and real-time quantitative PCR (QPCR) profiling were performed as described earlier $[38,39]$. We used custom-made transcriptome profilers
[40] pertaining to stemness and epithelial-to-mesenchymal transition (EMT) signaling.

\section{QPCR}

Total RNA extraction and individual gene QPCR were performed as described earlier [41, 42]. For this study, transcriptional alterations of Oct4, Zic3, EIF4C, Nanog, and LIF were investigated in polyphenol-treated ALDH ${ }^{+} \mathrm{CD} 44{ }^{+} \mathrm{CD} 24^{+} \mathrm{PC}-\mathrm{CSC}$ (derived from MiaPaCa-2 and Panc-1 xenografts) exposed to FIR.

\section{Immunoblotting}

We analyzed $\mathrm{ALDH}^{+} \mathrm{CD} 44^{+} \mathrm{CD} 24^{+}$PC-CSCs (derived from MiaPaCa-2, Panc-1, Panc-3.27, and BXPC-3 xenografts) grown ex vivo and exposed to SA-EA, PT-EA, or HT-EA fractions for the alterations in Nanog, Sox2, and Oct3/4 after $24 \mathrm{~h}$. Total protein extraction and immunoblotting were performed as described earlier [43].

\section{Tissue microarray construction and} immunohistochemistry/immunofluorescence

All tissue microarray (TMA) construction procedures were performed in the SCC Cancer Tissue Pathology Core. We examined the cellular localization and expression of N-Cadherin, OCT3/4, Sox2, LIF, PI3KR1, CD44, and Nanog. Appropriate tissue morphologic/pathologic (hematoxylin and eosin (H\&E)) controls and negative (no primary antibody) controls were examined in parallel. The slides were microdigitally scanned using a Scanscope and analyzed using Aperio Integrated Spectrum software (Leica Biosystems Inc., Buffalo Grove, IL, USA). For E-Cadherin, the primary protein is tagged with Mix-n-Stain ${ }^{\text {тM }} \mathrm{CF}^{\text {тм }} 488 \mathrm{~A}$ Antibody Labeling Kit (Sigma, St. Louis, MO), while the cell membrane was marked with wheat germ agglutinin (WGA)-Alexaflour-594 (Life Technologies Corporation, Grand Island, NY, USA) and nuclear counterstained with 4',6diamidino-2-phenylindole (DAPI). Immunofluorescence was measured in Operetta and analyzed with Columbus image data analysis.

\section{Oxidative stress assay}

A rapid and sensitive luminescent $\mathrm{H}_{2} \mathrm{O}_{2}$ assay (ROS-Glo ${ }^{\mathrm{Tm}}$ $\mathrm{H}_{2} \mathrm{O}_{2}$ Assay; Promega, Madison, WI, USA) was used to identify the efficacy of polyphenols in the regulation of PC-CSC oxidative stress. In brief, $\mathrm{ALDH}^{+} \mathrm{CD} 44^{+} \mathrm{CD} 24^{+}$ PC-CSCs (derived from $\mathrm{MiaPaCa}-2$ xenograft) grown ex vivo were treated with $100 \mu \mathrm{g} / \mathrm{ml} \mathrm{SA-EA}, \mathrm{PT}-\mathrm{EA}$, or HTEA and were allowed to incubate for $18 \mathrm{~h}$. The cells were then incubated with $\mathrm{H}_{2} \mathrm{O}_{2}(25 \mu \mathrm{M}$ final concentration) substrate solution for an additional $6 \mathrm{~h}\left(37^{\circ} \mathrm{C}, 5 \% \mathrm{CO}_{2}\right)$. The $\mathrm{H}_{2} \mathrm{O}_{2}$-proportional generated luciferin precursor was then converted to luciferin with L-cysteine and allowed to react (20 min in the dark) with Ultra Glo ${ }^{\mathrm{Tm}}$ recombinant luciferase, and the luminescence was quantified using a Synergy 
2 multimode reader (BioTek Instruments Inc., Winooski, VT, USA). Since polyphenols undergo abiotic reaction in cell culture medium and produce $\mathrm{H}_{2} \mathrm{O}_{2}[44,45]$, appropriate "no medium", "medium", "medium + drug", and "medium + cell" controls are included. All experiments were repeated three times and the background (no cells control) media factor normalized luminescence was compared between the groups using analysis of variance (ANOVA) with Bonferroni's posthoc comparison (GraphPad PRISM, La Jolla, CA, USA).

\section{Results}

Seaweed polyphenols inhibit PC-CSCs' cell viability ex vivo We analyzed MiaPaCa-2, Panc-1, Panc-3.27, and BxPC-3 cell-associated xenograft-derived PC-CSCs exposed to varying concentrations of SA-EA, PT-EA, or HT-EA for alterations in cell viability. PC-CSCs exposed to SA-EA, PT-EA, or HT-EA showed consistent inhibition of viability in concentrations as low as $10 \mu \mathrm{g} / \mathrm{ml}$ (Fig. 1b) in all four PC-CSC clones investigated. We observed a robust and dose-dependent inhibition of cell viability with increasing concentrations of SA-EA, PT-EA, or HT-EA with a maximum inhibition at $100 \mu \mathrm{g} / \mathrm{ml}$. Panc-1-derived PCCSCs were relatively very sensitive and demonstrated a linear dose-dependent inhibition of viability with the polyphenol treatment. All three polyphenols exerted a similar effect in this CSC clone. Other interesting observations include the following: while PT-EA exerted maximum effect in MiaPACa-2 ( 40\%), Panc-1 (>60\%), and Panc-3.27 (>40 \%) PC-CSCs, it exhibited relatively poor performance in Panc-3.27 PC-CSCs (>20\%); and SA-EA exerted maximum efficiency against BxPC-3 PC-CSCs $(\sim 60 \%)$ at a concentration as low as $20 \mu \mathrm{g} / \mathrm{ml}$ and did not show any further increase in activity with increasing concentrations (Fig. 1b). Together, these results demonstrate that the seaweed polyphenols inflict a profound inhibition on PCCSC cell viability.

\section{Seaweed polyphenols regulate the oxidative stress status of PC-CSCs}

To investigate whether the exposure of seaweed polyphenols alters the oxidative stress status of the PC-CSCs, MiaPaCa-2 xenograft-derived PC-CSCs maintained ex vivo were exposed to $100 \mu \mathrm{g} / \mathrm{ml}$ SA-EA, PT-EA, or HT-EA and analyzed for alterations in cell-generated $\mathrm{H}_{2} \mathrm{O}_{2}$ utilizing the Promega cell-based ROS-Glo ${ }^{\mathrm{Tm}} \mathrm{H}_{2} \mathrm{O}_{2}$ Assay. Since polyphenols undergo abiotic reaction in cell culture medium and produce $\mathrm{H}_{2} \mathrm{O}_{2}[44,45]$, appropriate in-house controls (no medium, medium, medium + drug, and medium + cell controls) are included. Compared with the untreated controls, all three polyphenols investigated exhibited a significant $(P<0.001)$ regulation of oxidative stress in PC-CSCs (Figure $\mathrm{S} 1 \mathrm{~B}$ in Additional file 1). Relatively we observed a robust effect with SA-EA in the regulation of oxidative stress in PC-CSCs.

\section{Therapy actuates stem cell-related transcriptome in PC- CSCs}

To characterize the heightened stemness of PC-CSCs that survive radiotherapy, we examined the modulations in 93 stem cell-related molecules in $\mathrm{ALDH}^{+} \mathrm{CD} 44^{+} \mathrm{CD} 24^{+} \mathrm{PC}$ CSCs that were derived from the xenografts established using genetically diverse MiaPaCa-2, Panc-1, Panc-3.27, and BXPC-3 cells. PC-CSCs maintained ex vivo were exposed to clinically relevant FIR. The FIR resulted in the robust ( $\geq 2$-fold) activation of $69,80,74$, and 77 stem cellrelated molecules in PC-CSCs of MiaPaCa-2, Panc-1, Panc-3.27, and BXPC-3 origin respectively (Additional file 2). Interestingly, 43 genes (ABCG2, $A C A N, A D A R$, ALDH1A1, ALDH2, ALPI, APC, ASCL2, AXIN1, BGLAP, BMP3, CD4, CD8A, CDC42, CDH1, COL2A1, COL9A1, CTNNA1, DTX1, DTX2, DVL1, FGFR1, GDF3, GJB1, GJB2, HDAC2, HRAS, ISL1, JAG1, MSX1, MYOD1, NOTCH2, NUMB, OCLN, PPARD, S1OOB, SHH, SNAI1, SNAI2, TBX2, TERT, TUBB3, TWIST1) showed robust cell line-independent upregulation (Additional file 2). Further, cell lines to genes traverse analysis identified an additional 34 genes showing cell line-independent upregulation in three cell lines, and another 11 genes showing such upregulation in two cell lines. Distinctively, GSK3B in MiaPaCa2-derived PC-CSCs and NCAM1 in Panc-3.27-derived PC-CSCs showed cell line-dependent activation. Together, these data demonstrate the activation of stem cell-related molecules in PC-CSCs that survive radiation.

\section{Seaweed polyphenols target therapy-activated stem cell- related transcription in $\mathrm{PC}-\mathrm{CSC}$.}

Next, we examined the transcriptional modulation of stem cell-related molecules in $\mathrm{ALDH}^{+} \mathrm{CD} 44^{+} \mathrm{CD} 24^{+} \mathrm{PC}-\mathrm{CSC}$ pretreated with SA-EA, PT-EA, and HT-EA, and exposed to FIR. SA-EA significantly inhibited 60 (of 80), 30 (of 74), 65 (of 77), and 59 (of 69) FIR-induced ( $\geq 2$-fold) stem cellrelated molecules in Panc-1, MiaPaCa-2, Panc-3.27, and BXPC-3-derived PC-CSCs respectively. While 11 of the 43 cell line-independent FIR-induced genes $(A P C, C D 8 A$, CDH1, COL9A1, CTNNA1, DVL1, GJB1, GJB2, ISL1, $O C L N, T B X 2)$ were completely suppressed by SA-EA treatment across all four PC-CSC clones investigated (Fig. $2 \neq$ ), we also observed a cell line-independent inhibition of 15 genes (ALDH1A1, ASCL2, AXIN1, BGLAP, CD4, DTX2, FGFR1, HDAC2, HRAS, JAG1, MSX1, PPARD, SNAI1, SNAI2, TUBB3) in at least three PC-CSC clones (Fig. 2†) and 16 other genes (ABCG2, $A C A N$, ADAR, ALDH2, ALPI, BMP3, CDC42, COL2A1, DTX1, GDF3, MYOD1, NOTCH2, NUMB, SHH, TERT, TWIST1) in two PC-CSC clones (Fig. 2*). However, cell linedependent inhibition of $S 100 \beta$ in PC-CSCs of BXPC-3 origin with SA-EA was also observed. Likewise, PT-EA treatment completely inhibited 46, 37, 43, and 65 of 80 , 74, 77, and 69 FIR-induced stem cell-related molecules in 


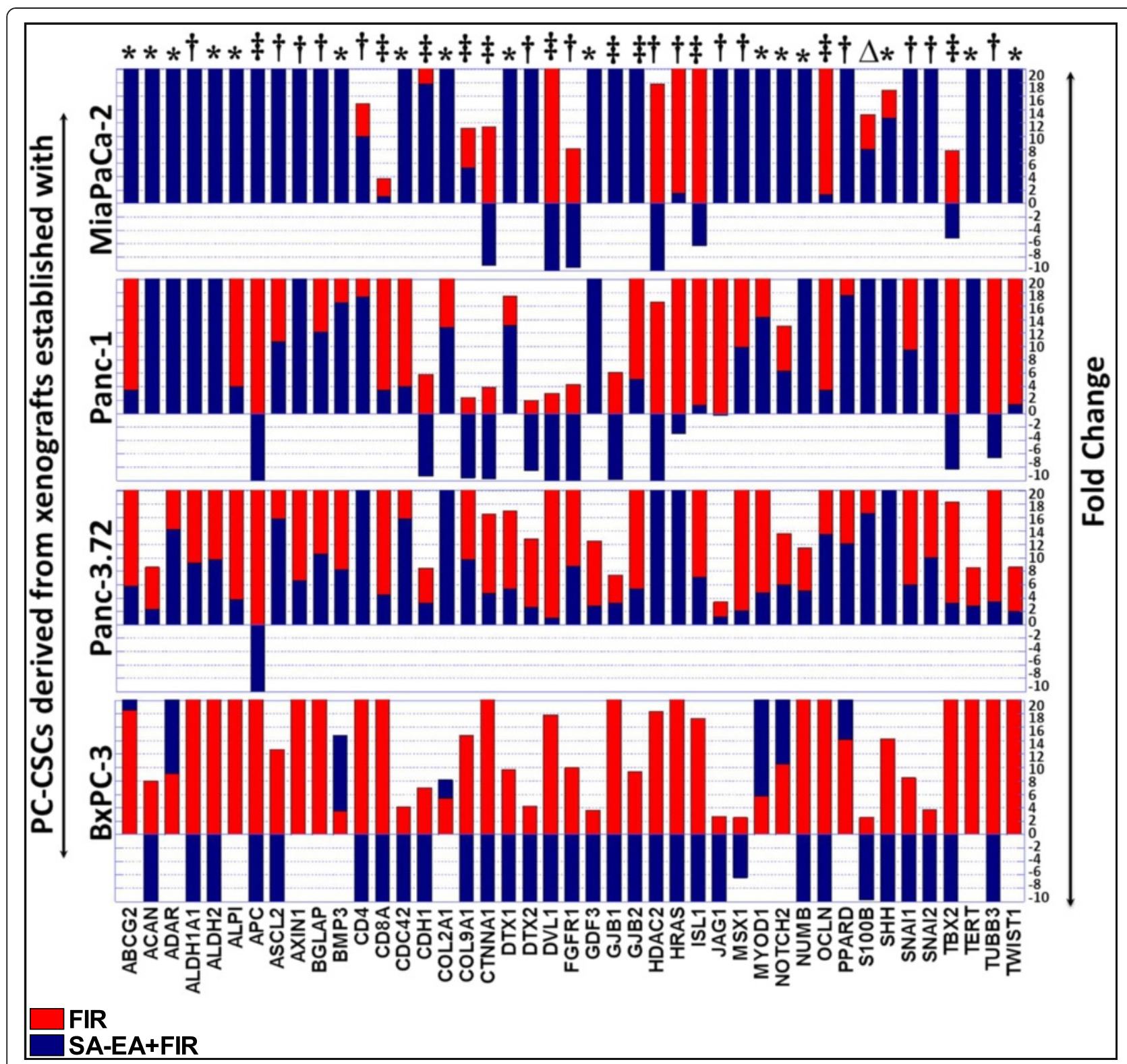

Fig. 2 Vertical stacked bars from QPCR profiling showing the regulation of FIR-amplified stem cell-related transcription with SA-EA treatment in $\mathrm{ALDH}^{+} \mathrm{CD} 44^{+} \mathrm{CD} 24^{+} \mathrm{PC}-\mathrm{CSC}$ derived from xenografts established using MiaPaCa-2, Panc-1, Panc-3.27, and BXPC-3. Inhibitory potential of SA-EA was compared for the 43 genes that showed cell line-independent increase after fractionated radiation across all four PC-CSC clones investigated. Cell line-independent effect of SA-EA for any given gene is indicated with " $\neq$ " for four, with " + " for three, and with "*" for two PC-CSC clones; " $\triangle$ " for cell line-dependent effect. In the stacked bar, SA-EA + FIR bars are overlaid on top of the FIR bars and the $y$ axis is restricted to a maximum of 20-fold for better presentation of comparative display. Overall, SA-EA treatment exerted cell line-independent inhibition of 11 of the 43 FIR-induced genes (APC, CD8A, CDH1, COL9A1, CTNNA1, DVL1, GJB1, GJB2, ISL1, OCLN, TBX2). CSC cancer stem cell, FIR fractionated irradiation, PC pancreatic cancer, SA-EA ethyl acetate polyphenol fraction of Spatoglossum asperum

Panc-1, MiaPaCa-2, Panc-3.27, and BXPC-3-derived PC-CSCs. However, of 43 cell line-independent FIRinduced genes, the comparison analysis revealed a cell line-independent inhibition of 10 genes $(A L D H 2, A P C$, AXIN1, DVL1, FGFR1, GJB2, HRAS, ISL1, TBX2, TUBB3) in all four PC-CSC clones (Fig. $3 \neq)$. In addition, a set of 17 genes (ABCG2, ADAR, ALPI, ASCL2, BGLAP, CD4, CD8A, COL9A1, CTNNA1, DTX1, DTX2, MSX1, MYOD1, OCLN,
PPARD, SNAI1, TWIST1) inhibited in common in at least three PC-CSC clones (Fig. 3+), while another 11 genes (ALDH1A1, BMP3, CDC42, COL2A1, GDF3, GJB1, HDAC2, JAG1, NUMB, SNAI2, TERT) were completely inhibited in two PC-CSCs with PT-EA (Fig. $3^{*}$ ). However, PT-EA silenced a small subset of genes (ACAN, S100 $\beta$, $S H H$ in BXPC-3; $C D H 1$ in MiaPaCa-2; NOTCH2 in Panc1 PC-CSC) in a cell line-dependent manner. Pretreating 


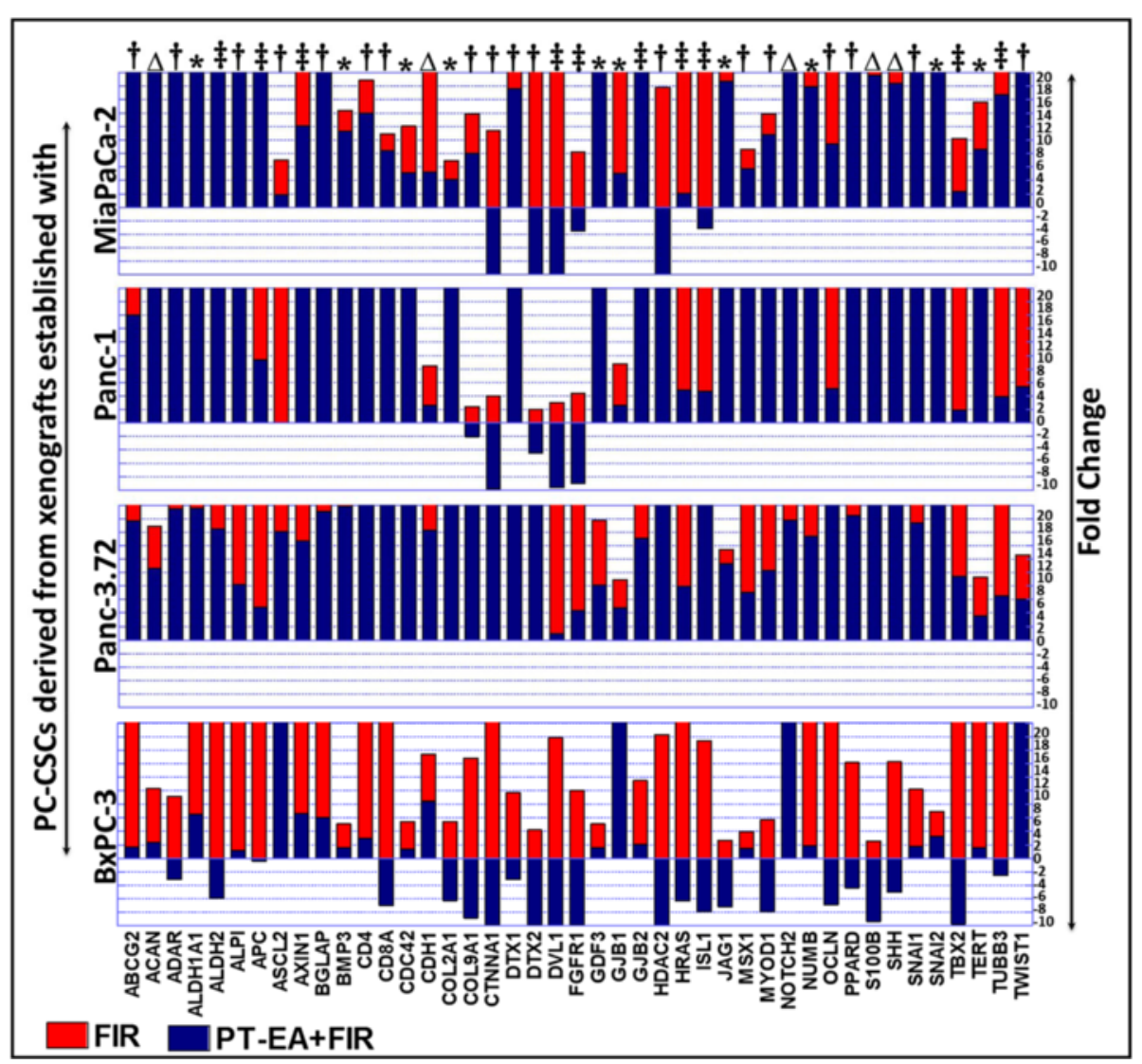

Fig. 3 Vertical stacked bars from QPCR profiling showing the regulation of FIR-amplified stem cell-related transcription with PT-EA treatment in $\mathrm{ALDH}^{+} \mathrm{CD} 44^{+} \mathrm{CD}_{24}{ }^{+} \mathrm{PC}-\mathrm{CSC}$ derived from xenografts established using MiaPaCa-2, Panc-1, Panc-3.27, and BXPC-3. Inhibitory potential of PT-EA was compared for the 43 genes that showed cell line-independent increase after fractionated radiation across all four PC-CSC clones investigated. Cell line-independent effect of PT-EA for any given gene is indicated with " $\neq$ " for four, with " $\dagger$ " for three, and with "**" for two PC-CSC clones; " $\Delta$ " for cell line-dependent effect. In the stacked bar, PT-EA + FIR bars are overlaid on top of the FIR bars and the $y$ axis is restricted to a maximum of 20-fold for better presentation of comparative display. Overall, PT-EA treatment exerted cell line-independent inhibition of 10 of the 43 FIRinduced genes (ALDH2, APC, AXIN1, DVL1, FGFR1, GJB2, HRAS, ISL1, TBX2, TUBB3). CSC cancer stem cell, FIR fractionated irradiation, PC pancreatic cancer, PA-EA ethyl acetate polyphenol fraction of Padina tetrastromatica

cells with HT-EA inhibited 80 (of 80), 72 (of 74), 75 (of 77), and 23 (of 69) FIR-induced stem cell-related molecules in Panc-1, MiaPaCa-2, Panc-3.27, and BXPC-3derived $\mathrm{ALDH}^{+} \mathrm{CD} 44^{+} \mathrm{CD} 24^{+} \mathrm{PC}-\mathrm{CSC}$. Interestingly, 14 of 43 FIR-induced genes (ALDH1A1, ALPI, APC, AXIN1, BGLAP, CD4, CDC42, CTNNA1, GJB1, HDAC2, HRAS, $J A G 1, S H H, T B X 2)$ were completely suppressed with HTEA treatment in all four PC-CSCs investigated (Fig. 4キ). We observed a significant cell line-independent inhibition of 29 (ABCG2, ACAN, ADAR, ALDH2, ASCL2, BMP3, CD8A, CDH1, COL2A1, COL9A1, DTX1, DTX2, DVL1, FGFR1, GDF3, GJB2, ISL1, MSX1, MYOD1, NOTCH2, NUMB, OCLN, PPARD, S100B, SNAI1, SNAI2, TERT, TUBB3, TWIST1) in three PC-CSCs with HT-EA treatment (Fig. 4†). Evidently, FIR-induced $A P C$ and $T B X 2$ were completely and consistently inhibited by all three seaweed polyphenols tested in all four PC-CSC clones investigated. Together, these data demonstrate the selective
FIR-induced stem cell-related transcriptome inhibitory potential of SA-EA, PT-EA, and HT-EA in PC-CSCs that survive radiotherapy.

\section{Seaweed polyphenols target radiotherapy-activated} EIF4C, OCT3/4, Nanog, LIF, and ZIC3 in PC-CSCs

To further recognize the regulation potential of seaweed polyphenols in the stem cell-related transcriptional machinery that drives EMT, pluripotency maintenance, and the self-renewal capacity of PC-CSCs, we examined the transcriptional modulations of EIF4C, OCT3/4, Nanog, LIF, and ZIC3 in PC-CSCs. SOX2, OCT3/4, Nanog, LIF, $E I F 4 C$, and ZIC3 comprise the core regulatory circuitry in stem cells that overturns differentiation-associated genes, and determines the improved stemness, pluripotency maintenance, and self-renewal capacity. Since these critical players (except for Sox2) are not included in the QPCR profiling, we investigated whether radiation 


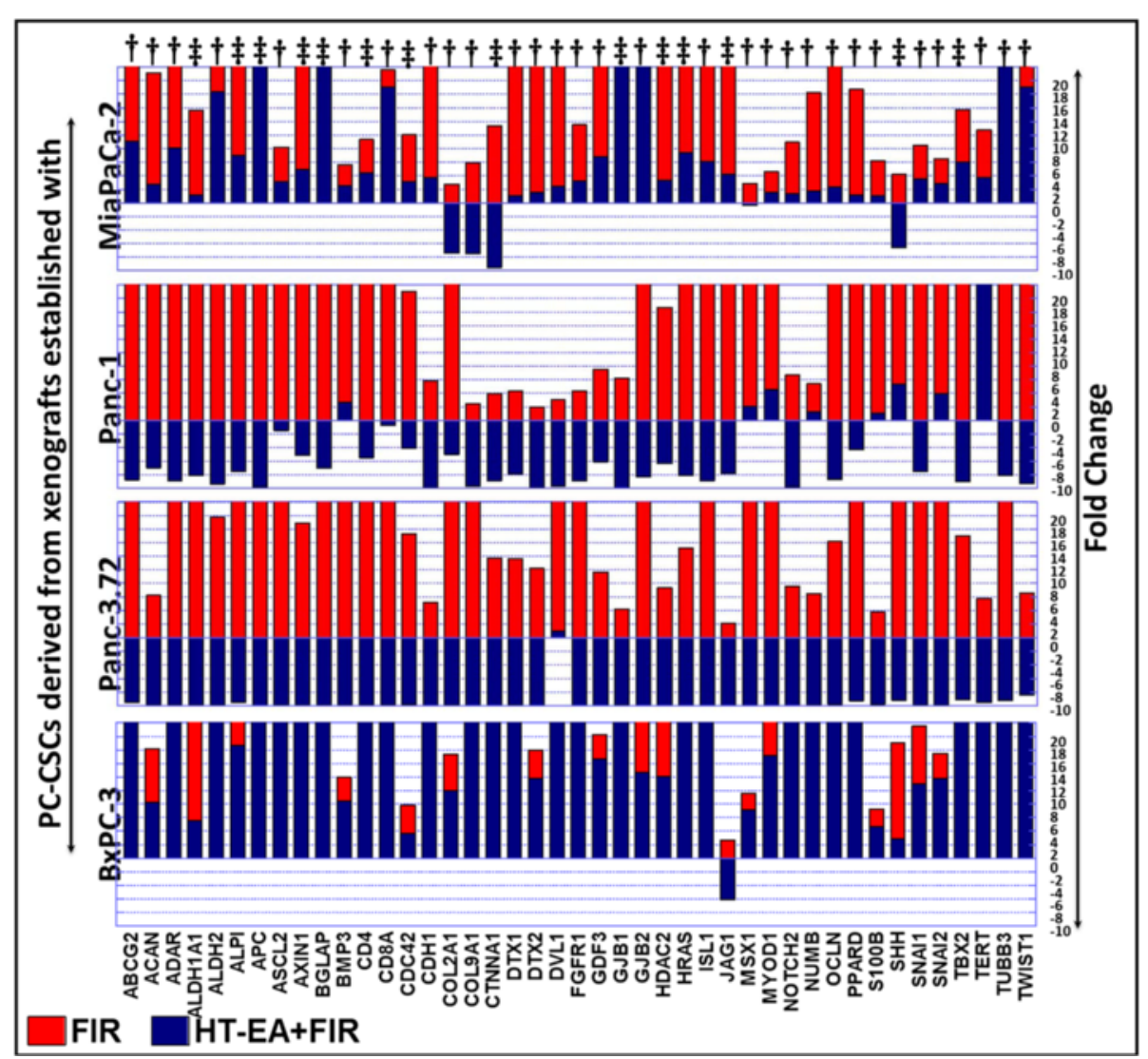

Fig. 4 Vertical stacked bars from QPCR profiling showing the regulation of FIR-amplified stem cell-related transcription with HT-EA treatment in $\mathrm{ALDH}^{+} \mathrm{CD} 44^{+} \mathrm{CD} 24^{+} \mathrm{PC}-\mathrm{CSC}$ derived from xenografts established using MiaPaCa-2, Panc-1, Panc-3.27, and BXPC-3. Inhibitory potential of HT-EA was compared for the 43 genes that showed cell line-independent increase after fractionated radiation across all four PC-CSC clones investigated. Cell line-independent effect of HT-EA for any given gene is indicated with " $\neq$ " for four, with " + " for three, and with "*" for two PC-CSC clones; " $\Delta$ " for cell line-dependent effect. In the stacked bar, PT-EA + FIR bars are overlaid on top of the FIR bars and the $y$ axis is restricted to a maximum of 20-fold for better presentation of comparative display. Overall, HT-EA treatment exerted cell line-independent inhibition of 14 of the 43 FIR-induced genes (ALDH1A1, ALPI, APC, AXIN1, BGLAP, CD4, CDC42, CTNNA1, GJB1, HDAC2, HRAS, JAG1, SHH, TBX2). CSC cancer stem cell, FIR fractionated irradiation, HT-EA ethyl acetate polyphenol fraction of Hormophysa triquerta, $P C$ pancreatic cancer

activates these stemness-maintenance markers in PCCSCs and further defined the benefit of seaweed polyphenols in mitigating such transcriptional/translational response. First, we examined the benefit of seaweed polyphenols in targeting EIF4C, OCT3/4, Nanog, LIF, and ZIC3 transcriptional activation as a standalone drug. For this, ex vivo maintained PC-CSCs (derived using MiaPaCa-2 and Panc-1 cells) were exposed to $100 \mu \mathrm{g} / \mathrm{ml}$ SA-EA, PT-EA, or HT-EA and examined after $24 \mathrm{~h}$. Overall, SA-EA, PT-EA, or HT-EA treatment exhibited a significant and consistent transcriptional inhibition of EIF4C, OCT3/4, Nanog, LIF, and ZIC3 in both MiaPaCa-2 and Panc-1-derived PC-CSCs (Figure S1C in Additional file 1). Evidently, SA-EA and PT-EA treatment exerted significant inhibition of OCT3/4, Nanog, and LIF in both PC-CSCs investigated. On the other hand, exposing the cells to HT-EA resulted in the complete inhibition of OCT3/4 in both PC-CSCs. Next, we examined the transcriptional modulation of EIF4C, OCT3/4, Nanog, LIF, and ZIC3 in MiaPaCa-2 and Panc-1-derived $\mathrm{ALDH}^{+} \mathrm{CD} 44$ ${ }^{+} \mathrm{CD} 24^{+}$PC-CSCs pretreated with SA-EA, PT-EA, and HT-EA, and exposed to radiotherapy. Therapy-associated activation of EIF4C in both PC-CSC clones was significantly inhibited in the presence of SA-EA, PT-EA, and HT-EA (Fig. 5a). Consistently, all three fractions inflict cell line-independent inhibition of FIR-induced OCT3/4 transcription in PC-CSCs (Fig. 5a). Moreover, we observed significant inhibition of Nanog transactivation in both PCCSCs with SA-EA, PT-EA, and HT-EA (Fig. 5a). Further, QPCR analysis recognized the definite inhibition of radiotherapy-induced LIF transactivation in PC-CSCs in the presence of seaweed polyphenols (Fig. 5a). Zic3 that was significantly activated in response to therapy was completely suppressed in PC-CSCs with SA-EA, PT-EA, or HT-EA (Fig. 5a). Immunoblotting revealed that the SA-EA, PT-EA, or HT-EA profoundly regulate therapy- 

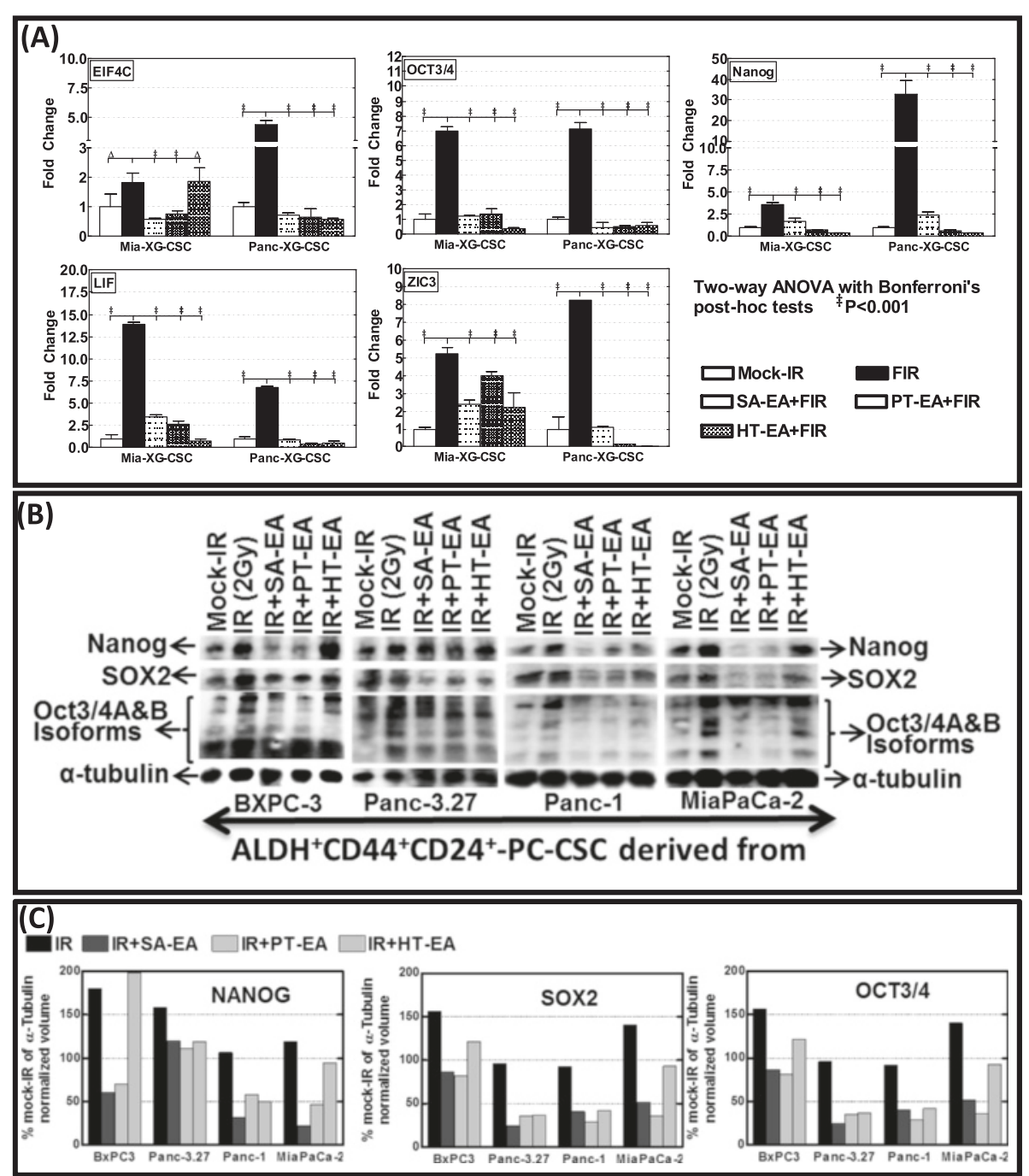

Fig. 5 a QPCR analysis showing mRNA levels of EIF4C, OCT3/4, Nanog, LIF, and ZIC3 in ALDH ${ }^{+} C D 44^{+} C D 24^{+}$PC-CSCs derived from xenografts of Panc-1 and MiaPaCa-2, either mock irradiated or exposed to FIR, with or without $100 \mu \mathrm{g} / \mathrm{ml} \mathrm{SA-EA,} \mathrm{PT-EA,} \mathrm{or} \mathrm{HT-EA.} \mathrm{b} \mathrm{Representative} \mathrm{immunoblots}$ showing expression levels of Nanog, Sox2, and Oct3/4 in Panc-1, MiaPaCa-2, Panc-3.27, and BXPC-3-derived ALDH ${ }^{+}$CD44 ${ }^{+}$CD24 $4^{+}$PC-CSCs, either mock irradiated or exposed to radiation, with or without SA-EA, PT-EA, or HT-EA. c Histograms show the Quantity-One densitometry of relative band intensities. ALDH aldehyde dehydrogenase, ANOVA analysis of variance, CSC cancer stem cell, FIR fractionated irradiation, HT-EA ethyl acetate polyphenol fraction of Hormophysa triquerta, PC pancreatic cancer, PT-EA ethyl acetate polyphenol fraction of Padina tetrastromatica, SA-EA ethyl acetate polyphenol fraction of Spatoglossum asperum

induced expression of pluripotency, maintaining Nanog, SOX2, and OCT3/4 in MiaPaCa-2, Panc-1, Panc-3.27, and BXPC-3-derived $\mathrm{ALDH}^{+} \mathrm{CD} 44^{+} \mathrm{CD} 24^{+}$PC-CSCs (Fig. 5b). Band intensity densitometry results corroborated well with the transcription data and recognized the potential of these drug deliverables in stemness-related functional response (Fig. 5c).

Seaweed polyphenols regulate SOX2, PI3KR1, OCT3/4, $\mathrm{N}$-Cadherin, E-Cadherin, Nanog, LIF, and CD44 in residual $\mathrm{PC}$ in vivo

To further substantiate our ex vivo findings, we examined the cellular expression/localization levels of SOX2,
PI3KR1, OCT3/4, N-Cadherin, E-Cadherin, Nanog, LIF, and CD44 in residual PC. SOX2 staining revealed basal levels $(0.31 \pm 0.13 \%)$ of positivity in mock-irradiated xenografts (Fig. 6). The positivity of SOX2 appeared in dark brown, and was principally localized in the nucleus (pullout in Additional file 3). SOX2 immunoreactivity was intense $(14.35 \pm 3.68 \%)$ in residual tumors after FIR (Fig. 6; Additional file 3). We observed a complete loss of FIRinduced SOX2 with SA-EA, PT-EA, or HT-EA (Fig. 6b). Expression of PIK3R1 was stronger in tumor cells than in stromal cells, and was predominantly localized in plasma membranes as well as in the cytoplasm (pullout in Additional file 4). Radiotherapy-treated xenografts 

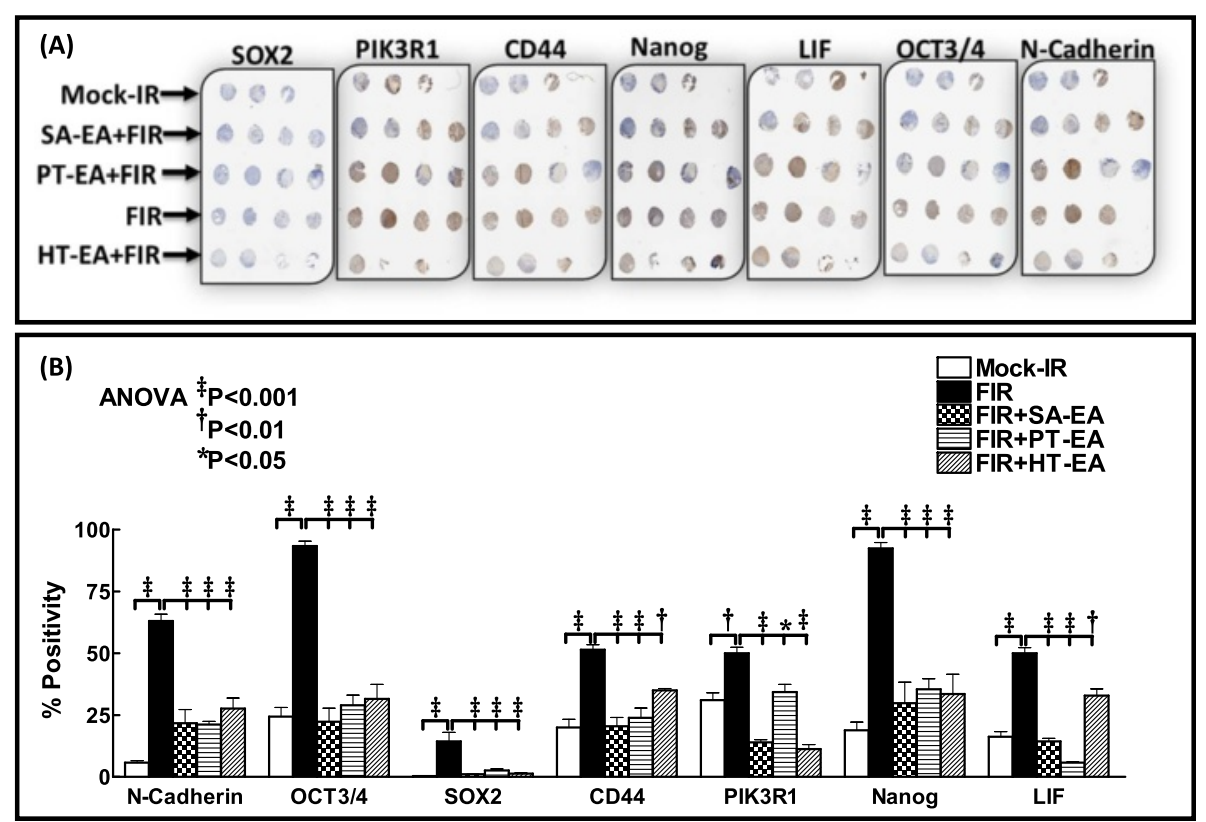

Fig. 6 a TMAs labeled for SOX2, PIK3R1, CD44, Nanog, LIF, OCT3/4, and N-Cadherin. b Aperio-TMA quantitation analysis showing protein-specific positivity magnitudes in mock-irradiated xenografts and residual PC tissues after radiotherapy, with or without SA-EA, PT-EA, or HT-EA. ANOVA analysis of variance, FIR fractionated irradiation, HT-EA ethyl acetate polyphenol fraction of Hormophysa triquerta, PT-EA ethyl acetate polyphenol fraction of Padina tetrastromatica, SA-EA ethyl acetate polyphenol fraction of Spatoglossum asperum

demonstrated strong $(49.98 \pm 2.38 \%)$ PIK3R1 expression (Fig. 6b; Additional file 4). Although SA-EA and PT-EA showed low levels of PIK3R1 compared with the FIR group, PIK3R1 was barely detectable with HT-EA treatment. OCT3/4-stained nuclei appeared in dark brown and were found mainly in epithelial cells (pullout in Additional file 5). OCT3/4 positivity ranged from $24.36 \pm 3.7 \%$ in mock-irradiated cells to $93.29 \pm 1.96 \%$ of irradiated residual tumors (Fig. 6b; Additional file 5). The range for OCT3/4-positive epithelial cells was 16-38 \% (SA-EA), $<30 \%$ (PT-EA), and $31.55 \pm 5.85 \%$ (HT-EA) with seaweed polyphenol treatment.

Positive staining of $\mathrm{N}$-Cadherin appeared in dark brown and was predominantly localized in cell membranes (pullout in Additional file 6). Compared with mock-IR, NCadherin immunoreactivity was intense in residual tumors after FIR (Fig. 6b; Additional file 6). We observed a significant $(P<0.001)$ reduction in $\mathrm{N}$-Cadherin immunoreactivity in the tumors of mice that received SA-EA, PT-EA, and HT-EA. Likewise, radiotherapy exerted intense Nanog immunoreactivity that was predominantly localized in the nucleus (pullout in Additional file 7). SA-EA, PT-EA, and HT-EA pretreatment showed weak nuclear Nanog (Fig. 6b; Additional file 7). LIF-positive staining appeared in brown, and was localized in plasma membranes, the cytoplasm, and nuclei (pullout in Additional file 8). However, radiotherapy-treated cells exhibited high LIF immunoreactivity. Regulation of the radiotherapy-induced LIF was evident in PC tissues of animals that received SA-EA,
PT-EA, and HT-EA (Fig. 6b; Additional file 8). CD44 immunoreactivity was highly intense and present in $>50 \%$ of the PC cells in residual tumors after FIR (Fig. 6b). The positivity of CD44 appeared in dark brown, and was predominantly localized in plasma membranes and the cytoplasm (pullout in Additional file 9 for granular cytoplasmic expression). Conversely, SA-EA, PT-EA, and HT-EA treatment exerted significant regulation of FIR-induced $\mathrm{CD} 44$ in residual $\mathrm{PC}$ tumors (Additional file 9). We observed a strong ECadherin immunoreactivity in mock-irradiated tumors. The positivity of E-Cadherin appeared in green, and was predominantly localized in plasma membranes and the cytoplasm (pullout in Additional file 10). Immunofluorescence was barely detectable $(<20 \%)$ in the PC cells in residual tumors after clinical doses of FIR (Additional file 10). Interestingly, treatment with SA-EA, PT-EA, and HT-EA following radiotherapy resulted on a profound increase in E-Cadherin localization in residual PC tumors.

\section{Discussion}

The results of this study demonstrated the survival and transcriptional activation of stem cell-related molecules in $\mathrm{ALDH}^{+} \mathrm{CD} 44^{+} \mathrm{CD} 24^{+} \mathrm{PC}$-CSCs after first-line therapy. For the first time, the results presented here defined the clinical potential of seaweed polyphenols in definite, comprehensive inhibition of stemness-related molecular turmoil in PC-CSCs surviving after therapy. Considering the magnitude of acquired (or via clonal 
selection) EMT/CSC physiognomies in PC cells that survive a course of therapy, the current study provides a molecular blueprint to underscore the importance of CSC targeting for a better PC cure. Although a number of studies have focused on identifying the role of $\mathrm{PC}$ CSCs in drug resistance [46, 47], the selection of CSC clones and/or acquired EMT-CSC phenotypes in response to therapy and their functional roles in PC relapse (or for that matter in any tumors) are poorly understood. To our knowledge, this study was the first of its kind portraying the amplified EMT/CSC-related molecular physiognomies after first-line therapy in PC. Moreover, this study employs both an in vivo preclinical approach and an ex vivo bench approach, and demonstrates the intensified stemness in the cells surviving after therapy. The results exposed highly comparable activation of stemness machinery between every PC-CSC clone, depicting a similar therapyassociated acquisition and/or enrichment of EMT/stem characteristics, regardless of the cell of origin.

Seaweed polyphenol (SA-EA, PT-EA, or HT-EA) treatment exerted a complete suppression of therapy-induced Nanog, Oct-4, and Sox-2 in PC-CSCs. These pluripotent CSCs maintaining Nanog, Oct-4, and Sox-2 exhibit tight interaction and regulate their own promoters, and along with other key developmental genes comprehensively form autoregulatory loops and functional signaling [48]. We observed significantly high levels of Nanog in therapy-resistant PC-CSCs ex vivo as well as in residual PC. Evidently, a high level of Nanog is a key regulator of stem cell self-renewal, pluripotency, and clonal expansion $[49,50]$ and it has been shown that Nanog-deficient cells lose their pluripotency [49]. Voluminous evidence implicates Nanog, Sox2, and OCT-4 in the stemness and pathogenesis of PC [51-53]. In the present study, the inhibition of therapy activated Nanog, SOX2, and OCT-4 by the seaweed polyphenol treatment, suggesting that comprehensive inhibition of these self-orchestrating CSC pluripotency maintaining factors could be a novel strategy to prevent stemness-maintenance in therapyresistant PC-CSCs.

In addition, the results of the present study portray for the first time the significant inhibition of therapyorchestrated N-Cadherin by the seaweed polyphenols. EMT, an event in which epithelial cells drop their characteristics and gain mesenchymal features, plays a crucial role in tumor progression. To that end, tumor metastasis requires the dissemination of CSCs from the primary site and subsequently colonizes in a distant site. In this regard, EMT has been shown to actively instigate stromal invasion, intravasation, dissemination, and colonization at distant sites, all crucial and mandatory events of metastasis. Notably, studies have shown that EMT predicts prognosis and contributes to the drug resistance in $\mathrm{PC}[54,55]$, and a number of EMT markers are recognized in PC [56].
Consistently, results of our study show a robust increase in the cellular levels of $\mathrm{N}$-Cadherin in residual PC after clinical doses of radiotherapy. Since its first implication for EMT in PC [57], several studies documented its importance and signaling in $\mathrm{PC}$ progression, and focused on identifying drug deliverables against $\mathrm{N}$-Cadherin [58-60]. However, thus far drug deliverables targeting EMT of drug/therapy resistant cells are still unexplored. To our knowledge, for the first time, the results of the present study demonstrate that the seaweed polyphenols inhibit the expression of $\mathrm{N}$-Cadherin in therapy-resistant residual tumors and further imply that these fractions could effectively target EMT-driven drug/therapy resistance in PC.

CSCs have been shown to play critical roles in drug resistance and tumor metastasis in many human malignancies including PC. It is now evident that PC-CSCs are resistant to well-defined chemotherapy and radiotherapy, and contribute to PC metastasis and recurrence after treatment by regenerating multiple cell types in the tumor through their maintained stemness. Since it is clear that the therapeutic failure/recurrence is due to ineffective targeting of the PC-CSC population, drug deliverables that selectively target PC-CSCs offer a greater promise for $\mathrm{PC}$ cure as well as prevention of recurrence. In this regard, the results of the present study defined the stemness-related molecular blue print in therapy-resistant PC-CSCs derived from primary tumors established with genetically diverse human PC cells. Moreover, this study identified the preclinical efficacy of seaweed polyphenols in targeting PC-CSC viability and therapy-associated activation of PC-CSC pluripotency and stemness-maintenance. The outcome of this study recognizes the potential benefits of these seaweed polyphenols as adjuvants for the current PC therapeutic modalities in place, but further studies with appropriate transgenic mouse models of spontaneous pancreatic carcinogenesis are warranted.

\section{Conclusions}

Remarkably, we identified significant benefits of the select high-polarity antioxidant-rich seaweed polyphenols in all-inclusive targeting of the intensified stemness in residual PC cells. The results defined the clinical efficacy of these polyphenols by demonstrating clone-independent inhibition of stem cell-related molecules. Since current conventional chemotherapy and radiotherapy are largely ineffective in depleting CSCs, identifying novel therapeutic strategies to selectively target CSCs is of utmost importance. Since aberrant reactivation of multiple signaling pathways is involved in the formation of PC-CSCs, identifying drugs that could target these events could be considered highly beneficial. Although many studies have focused on identifying the benefits of polyphenols from various sources to target the stem cell self-renewal 
capacity and pluripotency maintenance, these studies focused only on specific signaling events and understanding PC-CSCs before therapy. For the first time, this study identified three seaweed polyphenol extractions that possess proven anti-PC potential, and the ability to target the main signaling pathways that play critical roles in activating and/or maintaining CSCs after first-line therapy. In this regard, the results presented in this study are the front-runner for understanding the potential of polyphenols in therapy-orchestrated activation of PC-CSCs. However, further studies are needed to characterize these polyphenols in the perspective of pharmacokinetics, normal tissue cytotoxicity, in vivo bioavailability, and drug-delivering moieties to identify potential drug deliverables that could generate an archetypal shift in PC treatment practices.

\section{Additional files}

Additional file 1: Figure S1. A Representative photomicrographs showing the tumorosphere-forming capacity of $\mathrm{ALDH}^{+} \mathrm{CD} 44^{+} \mathrm{CD} 24^{+} \mathrm{PC}-$ CSCs. MiaPaCa-2 xenograft-derived PC-CSCs maintained ex vivo in serum free stem-cell culture conditions showing the cellular aggregation pattern and formation of organized tumorosphere. $\mathbf{B}$ Histograms obtained from rapid and sensitive luminescent $\mathrm{ROS}-\mathrm{GlO}^{\mathrm{TM}} \mathrm{H}_{2} \mathrm{O}_{2}$ Assay showing significant regulation of oxidative stress status in $\mathrm{ALDH}^{+} \mathrm{CD} 44^{+} \mathrm{CD} 24^{+} \mathrm{PC}-\mathrm{CSCS}$ (derived from MiaPaCa-2 xenograft) exposed to SA-EA, PT-EA, or HT-EA. Group-wise comparisons were made by ANOVA with Tukey's post-hoc correction using GraphPad PRISM. C Histograms of QPCR analysis showing mRNA levels of EIF4C, OCT3/4, Nanog, LIF, and ZIC3 in $\mathrm{ALDH}^{+} \mathrm{CD} 44^{+} \mathrm{CD} 24^{+}$ PC-CSCs derived from xenografts of Panc-1 and MiaPaCa-2 exposed with or without $100 \mu \mathrm{g} / \mathrm{ml}$ SA-EA, PT-EA, or HT-EA. Overall, seaweed polyphenols as a standalone compound significantly reduced the transcriptional activation of inhibited EIF4C, OCT3/4, Nanog, LIF, and ZIC3 in PC-CSCs. (PDF $1511 \mathrm{~kb}$ )

Additional file 2: Figure S2. Showing clinical doses of radiation (2 Gy/ day for 5 days, for a total dose of 10 Gy) significantly induced ( $\geq 2$-fold upregulation) EMT and stem cell-related transcriptome in PC-CSCs derived from Panc-1, Panc-3.27, MiaPaCa-2, or BxPC-3 cells' established xenografts. Forty-three genes (ABCG2, ACAN, ADAR, ALDH1A1, ALDH2, ALPI, APC, ASCL2, AXIN1, BGLAP, BMP3, CD4, CD8A, CDC42, CDH1, COL2A1, COL9A1, CTNNA1, DTX1, DTX2, DVL1, FGFR1, GDF3, GJB1, GJB2, HDAC2, HRAS, ISL1, JAG1, MSX1, MYOD1, NOTCH2, NUMB, OCLN, PPARD, S1OOB, SHH, SNAI1, SNAI2, TBX2, TERT, TUBB3, TWIST1) showed consistent cell lineindependent upregulation. (PDF $839 \mathrm{~kb}$ )

Additional file 3: Figure S3. Showing representative microphotographs from SOX2-stained PC TMA constructed with xenografts (established from $\mathrm{MiaPaCa}-2)$ exposed to mock irradiation or fractionated irradiation, with or without SA-EA, PT-EA, and HT-EA fractions. Pullout shows the staining pattern (20x magnification). (PDF $2283 \mathrm{~kb}$ )

Additional file 4: Figure S4. Showing representative microphotographs from PIK3R1-stained PC TMA constructed with xenografts (established from MiaPaCa-2) exposed to mock irradiation or fractionated irradiation, with or without SA-EA, PT-EA, and HT-EA fractions. Pullout shows the staining pattern (20× magnification). (PDF $2998 \mathrm{~kb}$ )

Additional file 5: Figure S5. Showing representative microphotographs from OCT3/4-stained PC TMA constructed with xenografts (established from MiaPaCa-2) exposed to mock irradiation or fractionated irradiation, with or without SA-EA, PT-EA, and HT-EA fractions. Pullout shows the staining pattern (20× magnification). (PDF $2892 \mathrm{~kb}$ )

Additional file 6: Figure S6. Showing representative microphotographs from N-Cadherin-stained PC TMA constructed with xenografts (established from MiaPaCa-2) exposed to mock irradiation or fractionated irradiation, with or without SA-EA, PT-EA, and HT-EA fractions. Pullout shows the staining pattern (20x magnification). (PDF $3032 \mathrm{~kb}$ )

Additional file 7: Figure S7. Showing representative microphotographs from Nanog-stained PC TMA constructed with xenografts (established from MiaPaCa-2) exposed to mock irradiation or fractionated irradiation, with or without SA-EA, PT-EA, and HT-EA fractions. Pullout shows the staining pattern (20× magnification). (PDF $4861 \mathrm{~kb}$ )

Additional file 8: Figure S8. Showing representative microphotographs from LIF-stained PC TMA constructed with xenografts (established from MiaPaCa-2) exposed to mock irradiation or fractionated irradiation, with or without SA-EA, PT-EA, and HT-EA fractions. Pullout shows the staining pattern (20x magnification). (PDF $2688 \mathrm{~kb})$

Additional file 9: Figure S9. Showing representative microphotographs from CD44-stained PC TMA constructed with xenografts (established from MiaPaCa-2) exposed to mock irradiation or fractionated irradiation, with or without SA-EA, PT-EA, and HT-EA fractions. Pullout shows the staining pattern (20× magnification). (PDF $2910 \mathrm{~kb}$ )

Additional file 10: Figure S10. Showing representative microphotographs from E-Cadherin-stained PC TMA constructed with xenografts (established from MiaPaCa-2) exposed to mock-irradiation or fractionated irradiation, with or without SA-EA, PT-EA, and HT-EA fractions. Pullout shows the staining pattern (20x magnification). (PDF $2643 \mathrm{~kb}$ )

\section{Abbreviations}

ALDH: Aldehyde dehydrogenase; ANOVA: Analysis of variance; CSC: Cancer stem cell; DAPI: 4',6-Diamidino-2-phenylindole; DMSO: Dimethyl sulfoxide; EGF: Epidermal growth factor; EMT: Epithelial-to-mesenchymal transition; FBS: Fetal bovine serum; FGF: Fibroblast growth factor; FIR: Fractionated irradiation; Gy: Gray, a derived unit of ionizing radiation; H\&E: Hematoxylin and eosin; HT-EA: Ethyl acetate polyphenol fraction of Hormophysa triquerta; PC: Pancreatic cancer; PT-EA: Ethyl acetate polyphenol fraction of Padina tetrastromatica; QPCR: Quantitative PCR; SA-EA: Ethyl acetate polyphenol fraction of Spatoglossum asperum; TMA: Tissue microarray; WGA: Wheat germ agglutinin.

\section{Competing interests}

The authors declare that they have no competing interests.

\section{Authors' contributions}

NA, STS, and TSH contributed to the conception and design of the experiments. SA, SKR, and STS contributed to the acquisition of the data. NA, SA, SKR, STS, and TSH contributed to data analysis and interpretation of the data. NA and SA drafted the manuscript, and SKR, STS, and TSH helped in revising it critically. All authors read and approved the final manuscript.

\section{Acknowledgements}

The authors were supported by research development funds from the Department of Radiation Oncology at University of Oklahoma Health Sciences to NA. The authors acknowledge the SCC Cancer Tissue Pathology Core for all TMA and immunohistochemistry services. The authors also acknowledge the OUHSC staff editor (Ms Kathy Kyler) for help in critically reviewing this manuscript.

\section{Author details}

'Department of Marine Sciences, Center of Advance Study in Marine Biology, Annamalai University, Parangipettai, TN 608 502, India. ${ }^{2}$ Stephenson Cancer Center, 975 NE 10th Street, Oklahoma City, OK 73104-5419, USA. ${ }^{3}$ Department of Radiation Oncology, University of Oklahoma Health Sciences Center, 940 Stanton L. Young Boulevard, Oklahoma City, OK 73104, USA.

Received: 24 February 2015 Revised: 25 February 2015 Accepted: 1 September 2015 Published online: 22 September 2015

\section{References}

1. McGinn CJ, Kinsella TJ. The experimental and clinical rationale for the use of S-phase-specific radiosensitizers to overcome tumor cell repopulation. Semin Oncol. 1992;19:21-8.

2. Hartomo TB, Kozaki A, Hasegawa D, Van Huyen PT, Yamamoto N, Saitoh A, et al. Minimal residual disease monitoring in neuroblastoma patients based 
on the expression of a set of real-time RT-PCR markers in tumor-initiating cells. Oncol Rep. 2013;29:1629-36.

3. Stutterheim J, Zappeij-Kannegieter L, Ora I, van Sluis PG, Bras J, den Ouden $E$, et al. Stability of PCR targets for monitoring minimal residual disease in neuroblastoma. J Mol Diagnost. 2012;14:168-75.

4. Yu F, Sim AC, Li C, Li Y, Zhao X, Wang DY, et al. Identification of a subpopulation of nasopharyngeal carcinoma cells with cancer stem-like cell properties by high aldehyde dehydrogenase activity. Laryngoscope. 2013;123:1903-11.

5. Torigoe T, Hirohashi Y, Yasuda K, Sato N. Constitutive expression and activation of stress response genes in cancer stem-like cells/tumour initiating cells: potent targets for cancer stem cell therapy. Int J Hyperthermia. 2013;29:436-41.

6. He K, Xu T, Xu Y, Ring A, Kahn M, Goldkorn A. Cancer cells acquire a drug resistant, highly tumorigenic, cancer stem-like phenotype through modulation of the PI3K/Akt/beta-catenin/CBP pathway. Int J Cancer. 2013;134:43-54.

7. Ischenko I, Seeliger H, Kleespies A, Angele MK, Eichhorn ME, Jauch KW, et al. Pancreatic cancer stem cells: new understanding of tumorigenesis, clinical implications. Langenbecks Arch Surg. 2010;395:1-10.

8. Vermeulen L, De Sousa EMF, van der Heijden M, Cameron K, de Jong JH, Borovski $T$, et al. Wnt activity defines colon cancer stem cells and is regulated by the microenvironment. Nat Cell Biol. 2010;12:468-76.

9. Chaffer CL, Brueckmann I, Scheel C, Kaestli AJ, Wiggins PA, Rodrigues LO, et al. Normal and neoplastic nonstem cells can spontaneously convert to a stem-like state. Proc Natl Acad Sci U S A. 2011;108:7950-5.

10. Campbell PJ, Yachida S, Mudie LJ, Stephens PJ, Pleasance ED, Stebbings LA, et al. The patterns and dynamics of genomic instability in metastatic pancreatic cancer. Nature. 2010:467:1109-13.

11. Yachida S, Jones S, Bozic I, Antal T, Leary R, Fu B, et al. Distant metastasis occurs late during the genetic evolution of pancreatic cancer. Nature. 2010;467:1114-7.

12. Notta F, Mullighan CG, Wang JC, Poeppl A, Doulatov S, Phillips LA, et al. Evolution of human BCR-ABL1 lymphoblastic leukaemia-initiating cells. Nature. 2011;469:362-7.

13. Bao S, Wu Q, McLendon RE, Hao Y, Shi Q, Hjelmeland AB, et al. Glioma stem cells promote radioresistance by preferential activation of the DNA damage response. Nature. 2006:444:756-60.

14. Todaro M, Alea MP, Di Stefano AB, Cammareri $P$, Vermeulen $L$, lovino F, et al. Colon cancer stem cells dictate tumor growth and resist cell death by production of interleukin-4. Cell Stem Cell. 2007;1:389-402.

15. Li X, Lewis MT, Huang J, Gutierrez C, Osborne CK, Wu MF, et al. Intrinsic resistance of tumorigenic breast cancer cells to chemotherapy. J Natl Cancer Inst. 2008;100:672-9.

16. Dylla SJ, Beviglia L, Park IK, Chartier C, Raval J, Ngan L, et al. Colorectal cancer stem cells are enriched in xenogeneic tumors following chemotherapy. PLoS One. 2008;3:e2428.

17. Morris JP, Wang SC, Hebrok M. KRAS, Hedgehog, Wnt and the twisted developmental biology of pancreatic ductal adenocarcinoma. Nat Rev Cancer. 2010;10:683-95.

18. Dubrovska A, Kim S, Salamone RJ, Walker JR, Maira SM, Garcia-Echeverria C, et al. The role of PTEN/Akt/PI3K signaling in the maintenance and viability of prostate cancer stem-like cell populations. Proc Natl Acad Sci U S A. 2009;106:268-73.

19. Zhou J, Wulfkuhle J, Zhang H, Gu P, Yang Y, Deng J, et al. Activation of the PTEN/mTOR/STAT3 pathway in breast cancer stem-like cells is required for viability and maintenance. Proc Natl Acad Sci U S A. 2007;104:16158-63.

20. Li C, Wu JJ, Hynes M, Dosch J, Sarkar B, Welling TH, et al. C-Met is a marker of pancreatic cancer stem cells and therapeutic target. Gastroenterology. 2011:141:2218-27.e2215.

21. Mueller MT, Hermann PC, Witthauer J, Rubio-Viqueira B, Leicht SF, Huber S, et al. Combined targeted treatment to eliminate tumorigenic cancer stem cells in human pancreatic cancer. Gastroenterology. 2009;137:1102-13.

22. Yoshie Y, W W, H P, S T. Compositional difference of phenolic compounds between two seaweeds, Halimeda spp. J Tokyo Univ Fish. 2002;88:21-4.

23. Furusawa $\mathrm{E}$, Furusawa $\mathrm{S}$. Anticancer activity of a natural product, vivanatural, extracted from Undaria pinnantifida on intraperitoneally implanted Lewis lung carcinoma. Oncology. 1985;42:364-9.

24. Yuan YV, Carrington MF, Walsh NA. Extracts from dulse (Palmaria palmata) are effective antioxidants and inhibitors of cell proliferation in vitro. Food Chem Toxicol. 2005;43:1073-81.
25. Makita H, Tanaka T, Fujitsuka H, Tatematsu N, Satoh K, Hara A, et al. Chemoprevention of 4-nitroquinoline 1-oxide-induced rat oral carcinogenesis by the dietary flavonoids chalcone, 2-hydroxychalcone, and quercetin. Cancer Res. 1996:56:4904-9.

26. Coombe DR, Parish CR, Ramshaw IA, Snowden JM. Analysis of the inhibition of tumour metastasis by sulphated polysaccharides. Int J Cancer. 1987:39:82-8.

27. Tanaka T. Cancer chemoprevention by natural-products (review). Oncol Rep. 1994;1:1139-55.

28. Zhang RL, Luo WD, Bi TN, Zhou SK. Evaluation of antioxidant and immunityenhancing activities of Sargassum pallidum aqueous extract in gastric cancer rats. Molecules. 2012;17:8419-29.

29. Yang Jl, Yeh CC, Lee JC, Yi SC, Huang HW, Tseng CN, et al. Aqueous extracts of the edible Gracilaria tenuistipitata are protective against $\mathrm{H}(2) \mathrm{O}(2)$-induced DNA damage, growth inhibition, and cell cycle arrest. Molecules. 2012;17:7241-54.

30. Liu F, Wang J, Chang AK, Liu B, Yang L, Li Q, et al. Fucoidan extract derived from Undaria pinnatifida inhibits angiogenesis by human umbilical vein endothelial cells. Phytomedicine. 2012;19:797-803.

31. Jayasooriya RG, Choi YH, Moon SK, Kim WJ, Kim GY. Methanol extract of Hydroclathrus clathratus suppresses matrix metalloproteinase-9 in T24 bladder carcinoma cells by suppressing the NF-kappaB and MAPK pathways. Oncol Rep. 2012;27:541-6.

32. Aravindan S, Delma CR, Thirugnanasambandan SS, Herman TS, Aravindan N. Anti-pancreatic cancer deliverables from sea: first-hand evidence on the efficacy, molecular targets and mode of action for multifarious polyphenols from five different brown-algae. PLoS One. 2013;8:e61977.

33. Veeraraghavan J, Natarajan M, Lagisetty P, Awasthi V, Herman TS, Aravindan N. Impact of curcumin, raspberry extract, and neem leaf extract on rel proteinregulated cell death/radiosensitization in pancreatic cancer cells. Pancreas. 2011:40:1107-19.

34. Rasheed Z, Wang Q, Matsui W. Isolation of stem cells from human pancreatic cancer xenografts. J Vis Exp. 2010;43:2169. doi:10.3791/2169.

35. Aravindan S, Natarajan M, Ramraj SK, Pandian V, Khan FH, Herman TS, et al. Abscopal effect of low-LET gamma-radiation mediated through Rel protein signal transduction in a mouse model of nontargeted radiation response. Cancer Gene Ther. 2014;21:54-9.

36. Aravindan S, Natarajan M, Awasthi V, Herman TS, Aravindan N. Novel synthetic monoketone transmute radiation-triggered NFkappaB-dependent TNFalpha cross-signaling feedback maintained NFkappaB and favors neuroblastoma regression. PLoS One. 2013;8:e72464.

37. Veeraraghavan J, Natarajan M, Aravindan S, Herman TS, Aravindan N Radiation-triggered tumor necrosis factor (TNF) alpha-NFkappaB crosssignaling favors survival advantage in human neuroblastoma cells. J Biol Chem. 2011;286:21588-600.

38. Aravindan N, Thomas Jr CR, Aravindan S, Mohan AS, Veeraraghavan J, Natarajan M. Irreversible EGFR inhibitor EKB-569 targets low-LET gammaradiation-triggered rel orchestration and potentiates cell death in squamous cell carcinoma. PLoS One. 2011;6:e29705.

39. Veeraraghavan J, Natarajan M, Herman TS, Aravindan N. Low-dose gamma-radiation-induced oxidative stress response in mouse brain and gut: regulation by NFkappaB-MnSOD cross-signaling. Mutat Res. 2011;718:44-55

40. Real Time Primers. LLC, 7304 Mountain Ave, Elkins Park, PA 19027. Copyright @ 2007 Realtimeprimers.com

41. Aravindan N, Madhusoodhanan R, Ahmad S, Johnson D, Herman TS. Curcumin inhibits NFkappaB mediated radioprotection and modulate apoptosis related genes in human neuroblastoma cells. Cancer Biol Ther. 2008;7:569-76.

42. Aravindan N, Aravindan S, Pandian V, Khan FH, Ramraj SK, Natt P, et al. Acquired tumor cell radiation resistance at the treatment site is mediated through radiation-orchestrated intercellular communication. Int J Radiat Oncol Biol Phys. 2014;88:677-85.

43. Natarajan M, Aravindan N, Meltz ML, Herman TS. Post-translational modification of I-kappa B alpha activates NF-kappa B in human monocytes exposed to 56Fe ions. Radiat Environ Biophys. 2002;41:139-44.

44. Long LH, Hoi A, Halliwell B. Instability of, and generation of hydrogen peroxide by, phenolic compounds in cell culture media. Arch Biochem Biophys. 2010;501:162-9.

45. Sang S, Hou Z, Lambert JD, Yang CS. Redox properties of tea polyphenols and related biological activities. Antioxid Redox Signal. 2005;7:1704-14 
46. Hermann PC, Huber SL, Herrler T, Aicher A, Ellwart JW, Guba M, et al. Distinct populations of cancer stem cells determine tumor growth and metastatic activity in human pancreatic cancer. Cell Stem Cell. 2007;1:313-23.

47. Wang Z, Li Y, Ahmad A, Banerjee S, Azmi AS, Kong D, et al. Pancreatic cancer: understanding and overcoming chemoresistance. Nat Rev Gastroenterol Hepatol. 2011:8:27-33.

48. Rodda DJ, Chew JL, Lim LH, Loh YH, Wang B, Ng HH, et al. Transcriptional regulation of nanog by OCT4 and SOX2. J Biol Chem. 2005;280:24731-7.

49. Mitsui K, Tokuzawa Y, Itoh H, Segawa K, Murakami M, Takahashi K, et al. The homeoprotein Nanog is required for maintenance of pluripotency in mouse epiblast and ES cells. Cell. 2003;113:631-42.

50. Chambers I, Colby D, Robertson M, Nichols J, Lee S, Tweedie S, et al. Functional expression cloning of Nanog, a pluripotency sustaining factor in embryonic stem cells. Cell. 2003;113:643-55.

51. Herreros-Villanueva M, Bujanda L, Billadeau DD, Zhang JS. Embryonic stem cell factors and pancreatic cancer. World J Gastroenterol. 2014;20:2247-54.

52. Lu Y, Zhu H, Shan H, Lu J, Chang X, Li X, et al. Knockdown of Oct4 and Nanog expression inhibits the stemness of pancreatic cancer cells. Cancer Lett. 2013;340:113-23.

53. Wen J, Park JY, Park KH, Chung HW, Bang S, Park SW, et al. Oct4 and Nanog expression is associated with early stages of pancreatic carcinogenesis. Pancreas. 2010:39:622-6.

54. Arumugam T, Ramachandran V, Fournier KF, Wang H, Marquis L, Abbruzzese $J \mathrm{~L}$, et al. Epithelial to mesenchymal transition contributes to drug resistance in pancreatic cancer. Cancer Res. 2009;69:5820-8.

55. Yamada S, Fuchs BC, Fujii T, Shimoyama Y, Sugimoto $H$, Nomoto $S$, et al. Epithelial-to-mesenchymal transition predicts prognosis of pancreatic cancer. Surgery. 2013:154:946-54.

56. Cates JM, Byrd RH, Fohn LE, Tatsas AD, Washington MK, Black CC. Epithelial-mesenchymal transition markers in pancreatic ductal adenocarcinoma. Pancreas. 2009:38:e1-6.

57. Nakajima S, Doi R, Toyoda E, Tsuji S, Wada M, Koizumi M, et al. N-cadherin expression and epithelial-mesenchymal transition in pancreatic carcinoma. Clin Cancer Res. 2004;10:4125-33.

58. Chiang KC, Yeh CN, Hsu JT, Jan YY, Chen LW, Kuo SF, et al. The vitamin D analog, MART-10, represses metastasis potential via downregulation of epithelial-mesenchymal transition in pancreatic cancer cells. Cancer Lett. 2014;354:235-44

59. Sun XD, Liu XE, Huang DS. Curcumin reverses the epithelial-mesenchymal transition of pancreatic cancer cells by inhibiting the Hedgehog signaling pathway. Oncol Rep. 2013;29:2401-7.

60. Li W, Ma J, Ma Q, Li B, Han L, Liu J, et al. Resveratrol inhibits the epithelialmesenchymal transition of pancreatic cancer cells via suppression of the PI-3 K/Akt/NF-kappaB pathway. Curr Med Chem. 2013;20:4185-94.

\section{Submit your next manuscript to BioMed Central and take full advantage of:}

- Convenient online submission

- Thorough peer review

- No space constraints or color figure charges

- Immediate publication on acceptance

- Inclusion in PubMed, CAS, Scopus and Google Scholar

- Research which is freely available for redistribution 